\title{
POTENCIAL DE GERAÇÃO DE ENERGIA ELÉTRICA A PARTIR DE SISTEMAS DE ENERGIA HELIOTÉRMICA NO ESTADO DE MINAS GERAIS
}

\section{ARTIGO ORIGINAL}

ASSIS, Matheus Miranda de ${ }^{1}$

CUNHA, Marcelo José Pereira da ${ }^{2}$

ASSIS, Matheus Miranda de. CUNHA, Marcelo José Pereira da. Potencial de geração de Energia Elétrica a partir de sistemas de energia heliotérmica no Estado de Minas Gerais. Revista Científica Multidisciplinar Núcleo do Conhecimento. Ano 05, Ed. 06, Vol. 01, pp. 19-43. Maio de 2020. ISSN: 2448-0959, Link de acesso: https://www.nucleodoconhecimento.com.br/engenharia-ambiental/potencialde-geracao

\section{RESUMO}

Diante do crescente consumo de energia elétrica vivenciado atualmente pela sociedade, há uma demanda cada vez maior na diversificação da matriz energética utilizando-se fontes renováveis. Ante este cenário, o presente trabalho analisa e avalia, com auxílio de análise espacial em Sistema de Informação Geográfica (SIG) utilizando os aplicativos Quantum Gis e ArcGis, os locais mais propensos à instalação de usinas heliotérmicas no estado de Minas Gerais. Foi feita uma revisão bibliográfica dos modelos de sistemas heliotérmicos, apontando o modelo de torre central como o mais vantajoso e eficiente em relação aos demais. O cruzamento de dados de irradiação direta normal disponibilizados pelo Solar and Wind Energy Resource Assessment (SWERA), base cartográfica do estado de Minas Gerais, base

\footnotetext{
${ }^{1}$ Engenheiro Ambiental e Sanitarista.

${ }^{2}$ Engenheiro de Agrimensura e Analista em desenvolvimento e reforma agrária.
} 
cartográfica de hidrografia e linhas de transmissão de energia elétrica, modelo digital de elevação elaborado a partir de dos dados do Shuttle Radar Topograpy Mission (SRTM) disponibilizadas pela United States Geological Survey (USGS) e, por fim, o quantitativo e espacialização de indústrias instaladas por município indicou duas regiões em Uberlândia/MG, como locais mais propensos à instalação de uma usina heliotérmica no estado.

Palavras-chaves: Energia termosolar, sistema de informação geográfica, análise espacial.

\section{INTRODUÇÃO}

O desenvolvimento econômico do planeta tem provocado um crescente aumento do consumo de energia. Visto que há cada vez mais cobranças no que se refere ao aquecimento global, observa-se uma necessidade cada vez maior de prover esta demanda com fontes de energias renováveis, como eólica, solar e biomassa (CAMAROS; OLIVEIRA; SHAYANI, 2016).

Segundo a International Renewable Energy Agency (IRENA, 2017), em 2016, a energia solar no mundo teve um aumento de 70.873 MWe em relação ao ano de 2015, representando $13,9 \%$ de toda energia produzida globalmente dentre outras fontes renováveis.

A Alemanha, no momento a maior economia da Europa, está entre os países que mais investem na matriz de energia solar, e sua região mais ensolarada possui um índice de radiação 40\% menor que a região menos ensolarada do Brasil (CEPEL, [entre 2013 e 2016]; CABRAL; SENNA; TORRES, 2013).

Segundo a Agência Nacional de Energia Elétrica (ANEEL, 2017), a matriz elétrica brasileira é dividida em: hidrelétrica $(68,1 \%)$, biomassa $(8,2 \%)$, eólica $(5,4 \%)$, solar $(0,01 \%)$, gás natural $(9,1 \%)$, derivados de petróleo $(3,7 \%)$, nuclear $(2,6 \%)$ e carvão e derivados (2,9\%). Segundo o Portal Brasil (2017), a energia solar obteve um 
crescimento de $8,4 \%$ entre novembro de 2015 e 2016, demonstrando o constante avanço da fonte solar, mesmo com a crise econômica vivenciada pelo cenário atual.

Por estar localizado em uma região vicinal à linha equatorial, o Brasil apresenta baixas variações nos índices de incidência solar ao longo do ano, tornando seu território muito propenso a instalação de sistemas que aproveitem a irradiação solar como fonte de energia (SILVA; SOUZA, 2016).

Atualmente diversos governos e organizações não governamentais têm estimulado o desenvolvimento e uso de tecnologias que promovam o maior aproveitamento energético da irradiação solar. Entre as tecnologias mais conhecidas está a energia solar fotovoltaica, e seu funcionamento baseia-se na conversão da irradiação solar em eletricidade por meio de materiais semicondutores (KEMERICH, 2016).

Outra tecnologia promissora é a energia heliotérmica, também chamada de Concentrated Solar Power (CSP). Bastante similar à termoelétrica convencional, este modelo baseia-se na utilização de espelhos estrategicamente posicionados sobre 0 solo que recebem e concentram a radiação solar à um receptor central. Neste receptor circula um fluido (ar, água, sais ou óleo) que ao ser aquecido pela radiação atinge altas temperaturas, promovendo um aumento de pressão no sistema, consequentemente gerando energia mecânica que posteriormente será convertida em energia elétrica (LODI, 2011).

O presente trabalho visa identificar as regiões do estado de Minas Gerais mais propensas à instalação de sistemas heliotérmicos com base em dados de irradiação direta normal, declividade do terreno, disponibilidade de água, proximidade às linhas de transmissão e áreas de conservação da natureza.

\section{REFERENCIAL TEÓRICO}

O funcionamento de sistemas heliotérmicos segue a premissa básica de reflexão e concentração de raios solares em receptores centrais, que possuem superfície menor, de forma a se obter a maior temperatura possível para um pleno funcionamento do

Disponível em: https://www.nucleodoconhecimento.com.br/engenharia-ambiental/potencial-de- 
sistema. Atualmente empregam-se quatro modelos de sistemas heliotérmicos, os quais serão discutidos a seguir.

\subsection{CILÍNDRICO PARABÓLICO OU PARABÓLICO LINEAR}

Considerado a tecnologia mais madura entre as no momento utilizadas, é formado basicamente por um conjunto de espelhos curvados interligados em formato parabólico com até 100 metros de extensão, ligados à um sistema de rastreamento de radiação solar de eixo único; posicionados em canais de várias colunas paralelas de Norte ao Sul. Seus refletores apresentam diâmetro de 5 a 6 metros. Comumente, seu receptor central de calor é composto por um tubo de vidro em vácuo (para reduzir as perdas de calor) com um tubo de aço inoxidável em seu interior, aplicado com um revestimento negro por onde atravessa um fluido, como óleos sintéticos, que podem atingir temperaturas de até $390^{\circ} \mathrm{C}$. O revestimento aplicado no tubo apresenta alto nível de absorção do coeficiente de radiação e refletividade de aproximadamente 5\% (SILVA, 2013; PHILIBERT et al, 2010).

O óleo circula em circuito fechado e é encaminhado à um permutador onde sua energia térmica é utilizada para aquecer a água e gerar vapor a altas pressões. Em seguida, o vapor gerado alimenta uma turbina interligada a um gerador produzindo energia elétrica. Finalmente, o vapor é encaminhado a condensadores que reduzem sua temperatura e o retornam ao processo em um ciclo fechado (SILVA, 2013).

Segundo Bianchini (2013), as usinas deste modelo de maior capacidade atualmente em operação conseguem gerar até $100 \mathrm{MW}$ de eletricidade, como a usina Shams 1 em operação desde 2013 nos Emirados Árabes.

\subsection{DISCO PARABÓLICO}

Utilizando espelhos em formato de discos parabólicos - também chamados de pratos parabólicos - este sistema reflete a radiação direta recebida à um receptor central, localizado em seu ponto focal. A radiação direta aquece o receptor central por onde 
circula um fluido de trabalho, que acionará um motor de ciclo Stirling[3]; para só então acionar um gerador (BIANCHINI, 2013).

Segundo Kalogirou (2009), o sistema parabólico pode atingir temperaturas acima dos $1.500^{\circ} \mathrm{C}$, atingindo as maiores temperaturas entre todos os sistemas e podem ser instalados como sistemas unitários ou em larga escala, sendo indicados para regiões mais isoladas.

\subsection{FRESNEL}

O sistema Compact Linear Fresnel Reflector (CLFR) e também conhecido apenas como Fresnel, apresenta espelhos estreitos e longos com superfície plana ou levemente curvada, dispostos de forma alinhada e segmentada, exibindo características próximas ao sistema cilíndrico parabólico. Este sistema apresenta seus receptores de radiação logo acima dos espelhos. O modelo pode operar a temperaturas de até $200^{\circ} \mathrm{C}$ (LODI, 2011; PENAFIEL, 2011).

Uma das vantagens deste modelo está nos baixos custos em sua instalação e operação, já que seus espelhos refletores apresentam design simples, facilitando sua fabricação. A geração de vapor ocorre nos próprios receptores, eliminando a necessidade de fluidos de transferência e permutadores de calor (PHILIBERT et al, 2010; SILVA, 2013).

\subsection{TORRE CENTRAL}

Conhecido também como Central Receiver System (CRS), é composto por um conjunto de espelhos planos distribuídos geralmente em forma de campo solar circular, controlados eletronicamente para rastrearem o sol. Os espelhos se movem em dois eixos de forma independente, refletindo o máximo de radiação possível a um receptor de calor, localizado no topo de uma torre central (LODI, 2011).

Segundo Lodi (2011), ao absorver calor a temperaturas de $800^{\circ} \mathrm{C}$ a $1.000^{\circ} \mathrm{C}$ o receptor o transfere a um fluido circulante (vapor, ar ou sais fundidos). $\mathrm{O}$ fluido aquecido é 
conduzido para um bloco de potência, onde é gerado vapor superaquecido acionando uma turbina e gerando eletricidade (BIANCHINI, 2013).

As altas temperaturas que este sistema é capaz de atingir permite a utilização de turbinas de alta potência, o que para Bianchini (2013), Ihe proporciona "maior eficiência de conversão de energia mecânica na turbina de vapor para energia elétrica no gerador".

\section{METODOLOGIA}

Este estudo foi desenvolvido com base em artigos científicos, publicações, livros e dados históricos e geoespaciais de instituições nacionais e internacionais.

Os Sistemas de Informação Geográfica (SIG) configuram-se em uma poderosa ferramenta de acesso, classificação, medição, superposição de mapas, análise de vizinhança, análise de conectividade, construção de mapas derivados e auxílio na tomada de decisão. Considerando que neste trabalho, o objeto principal é a escolha ou indicação de áreas mais prováveis para instalação de uma usina heliotérmica no estado de Minas Gerias, uma gama bem variada de temas teve que ser considerados e a utilização do SIG foi de fundamental importância no cruzamento dos dados, filtragem e convergência ao objeto.

Os SIG utilizados neste trabalho foram o Quantum GIS vr. 2.18 e o ArcGis vr. 10.3. Para escolha de locais que propiciem condições ideais e eficiência à instalação de sistemas heliotérmicos, devem ser analisados parâmetros como: níveis de irradiação direta incidente na área; declividade do terreno; disponibilidade de água e proximidade às linhas de transmissão e unidades de conservação da natureza.

\subsection{PROJETO SWERA}

Como fonte de informações destacam-se aquelas levantadas pelo projeto Solar and Wind Energy Resource Assessment (SWERA), que tem como principal objetivo facilitar a inserção de fontes de energias renováveis nos países que investiram no 
projeto - entre eles o Brasil - disponibilizando mapas de irradiação direta normal fundamentais para avaliação de locais propensos à instalação de sistemas de energia heliotérmica. O responsável pela coordenação do projeto no Brasil é o Centro de Previsão do Tempo e Estudos Climáticos (CPTEC/INPE) através da Divisão de Clima e Meio Ambiente (DMA).

Todos os mapas de irradiação gerados pelo projeto SWERA são disponibilizados como produtos e ferramentas em plataformas de Sistema de Informação Geográfica (PEREIRA et al, 2005).

\subsection{FATORES AMBIENTAIS}

A escolha do local a ser instalado um sistema heliotérmico depende diretamente dos fatores ambientais que serão explicitados a seguir; e o atendimento aos pré-requisitos destes, garantirá eficiência e economia na instalação e operação das usinas.

\subsection{IRRADIAÇÃO DIRETA NORMAL}

Principal fator na escolha de locais propensos à instalação de sistemas heliotérmicos, e parâmetro utilizado nos mapas do projeto SWERA abordado neste estudo, a irradiação direta normal, ou DNI (do inglês, Direct Normal Irradiance), é definida como a irradiação emitida pelo sol que ao atravessar a atmosfera terrestre não sofre nenhum tipo de desvio; e quando o céu está totalmente coberto por nuvens seu valor é igual a 0 (ENERGIA HELIOTÉRMICA, 2015).

Segundo Philibert et al. (2010), para que um sistema heliotérmico seja eficiente, os fabricantes estabelecem um limite mínimo de DNI de $1.900^{\frac{\mathrm{kWh}}{\mathrm{m}^{2}} / \mathrm{ano}}$ a 2.100 $\frac{\mathrm{kWh}}{\mathrm{m}^{2}} / \mathrm{ano}$.

Abaixo destes valores os sistemas heliotérmicos não apresentariam vantagens sobre outros sistemas de energia solar, como sistemas fotovoltaicos. 


\subsection{DECLIVIDADE DO TERRENO}

Para evitar gastos excessivos com terraplanagem no local de instalação da usina, Penafiel (2011) ressalta a importância de escolher locais onde o terreno tenha pouca declividade, ou seja, relevo plano.

\subsection{DISPONIBILIDADE DE ÁGUA}

Considerada um relevante parâmetro na escolha de áreas para instalação de sistemas heliotérmicos, a água é utilizada nos processos de refrigeração dos vapores e limpeza dos espelhos refletores das plantas; e dependendo do modelo, é de suma importância sua disponibilidade em larga escala (PHILIBERT et al, 2010).

Para sistemas parabólicos e de Fresnel que foram explicitados no item 2, são necessários para todo o processo aproximadamente $3.000 \mathrm{l} / \mathrm{MWh}$. Para sistemas em formato de torre, o consumo de água por MWh depende da eficiência da tecnologia aplicada; e nestes, o sistema de resfriamento é feito por ar circulante, dispensando o uso de água e reduzindo o consumo total nas plantas CSP (PHILIBERT et al, 2010).

Os dados hidrográficos contendo as localizações de cursos d'água do estado de Minas Gerais foram obtidos junto ao Instituto Mineiro de Gestão das Águas (IGAM).

\subsection{PROXIMIDADE ÀS LINHAS DE TRANSMISSÃO, SUBESTAÇÕES E CENTROS DE CARGA}

Para viabilidade econômica e redução de custos, é imprescindível avaliar a distância da usina à centrais, linhas de transmissão e subestações de energia; já que a construção destes sistemas apresenta valores muito elevados (AZEVEDO; TIBA; CANDEIAS, 2010).

A localização das linhas de transmissão do sistema elétrico do estado de Minas Gerais foram adquiridas no Sistema de Informações Geográficas do Setor Elétrico (SIGEL), sistema administrado pela ANEEL. 


\subsection{UNIDADES DE CONSERVAÇÃO AMBIENTAL}

Visando a conservação das áreas naturais, foi instituído através Lei oㅡ 9.985, de 18 de julho de 2000, o Sistema Nacional de Conservação da Natureza (SNUC), com objetivo de criar e gerir Unidades de Conservação da Natureza (UC's); sejam elas federais, estaduais ou municipais.

De acordo ainda a Lei supracionada, as UC's podem ser definidas como:

Espaço territorial e seus recursos ambientais, incluindo as águas jurisdicionais, com características naturais relevantes, legalmente instituído pelo Poder Público, com objetivos de conservação e limites definidos, sob regime especial de administração, ao qual se aplicam garantias adequadas de proteção.

Devido à necessidade de supressão vegetal nas áreas de instalação e operação de sistemas heliotérmicos, neste trabalho, as regiões que contiverem UC's serão descartadas.

\subsection{ANÁLISE ESPACIAL}

A análise espacial em um Sistema de Informação Geográfica é a capacidade de mensurar propriedades e relacionamentos, considerando a localização espacial do fenômeno em estudo, com aplicação de procedimentos encadeados cuja finalidade é obter uma informação que permita a tomada de decisão a partir de um conjunto de informações sobrepostas ou inter-relacionadas.

O parâmetro inicial para análise espacial aqui conduzida, foi definir o valor mínimo de irradiação direta normal (DNI) a ser considerada, tendo em vista a necessidade de estabelecer critérios que propiciem uma produção eficiente de energia elétrica. Com base nos parâmetros explicitados no item 3.3, considerou-se a média entre o intervalo mínimo definido pelos fabricantes, ou seja, o valor de $2.000 \frac{\mathrm{kWh}}{\mathrm{m}^{2}} / \mathrm{ano}$. 
Os dados do projeto SWERA utilizados apresentam-se em formato shapefile, em forma matricial, cobrindo todo o território nacional brasileiro. Cada célula da matriz possui $10 \mathrm{~km}$, em ambos os eixos. A tabela de atributos que acompanha $\mathrm{o}$ arquivo shapefile apresenta dados médios mensais e anuais de DNI para cada uma das células. Importante observar que, os valores médios para cada uma das células são representados em função da média diária, desta forma, necessário se faz que o valor mínimo de DNI definido inicialmente com a escala anual $\left(2.000^{\frac{\mathrm{kWh}}{\mathrm{m}^{2}} / \mathrm{ano}}\right)$ seja convertido para escala diária. Assim:

$$
\begin{gathered}
D N I_{\text {diário }}=\frac{\frac{2.000 \mathrm{kWh}}{\mathrm{m}^{2}} / \mathrm{ano}}{365 \text { dias }} \\
D N I_{\text {diário }}=5,48 \frac{\mathrm{kWh}}{\mathrm{m}^{2}} / \mathrm{dia}
\end{gathered}
$$

De posse dos dados de DNI para o estado de Minas Gerais, foi realizada uma análise espacial por atributos tendo como condição para a filtragem o valor de DNI igual ou superior a 5,48 $\frac{\mathrm{kWh}}{\mathrm{m}^{2}} /$ dia, o que garante uma incidência de irradiação solar no local de pelo menos $2.000^{\frac{\mathrm{kWh}}{\mathrm{m}^{2}} / \mathrm{ano} \text {. }} \mathrm{e}$, consequentemente, torna o projeto de instalação de uma usina heliotérmica viável, como já explicitado. O Mapa 01 (Map 01 - Irradiation map of Minas Gerais state) e 02 (Map 02 - Filtered map for minimum conditions of Direct Normal Irradiation at Minas Gerais state) abaixo ilustram os resultados antes e após a análise espacial supracitada. 

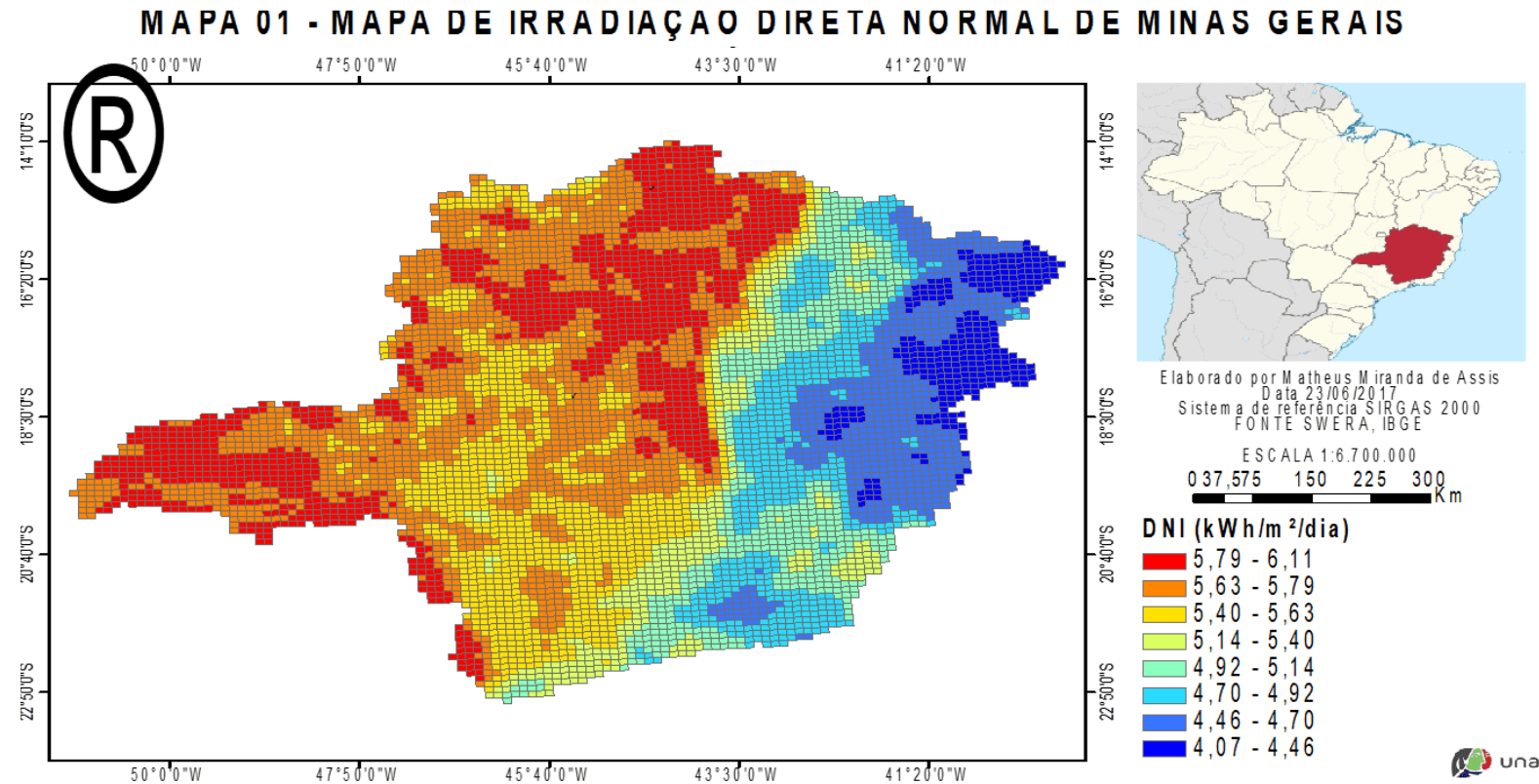

MAPA 02 - MAPA FILTRADO PARA AS CONDIÇÕES MÍNIMAS DE DNI EM MINAS GERAIS

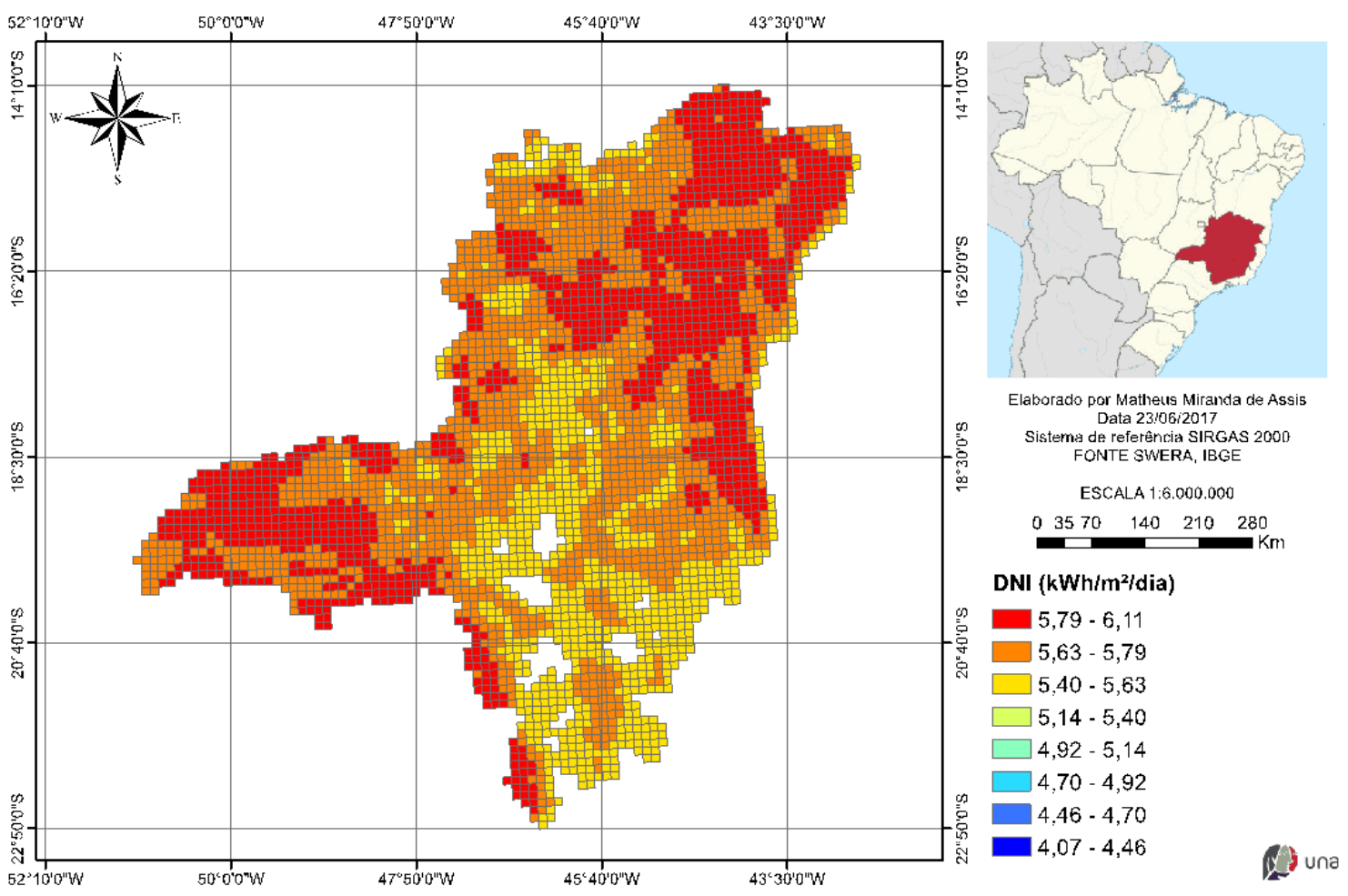

Disponível em: https://www.nucleodoconhecimento.com.br/engenharia-ambiental/potencial-degeracao 
Com o mapa construído no passo anterior (valores de $\mathrm{DNI} \geq 5,48$ ) foram sobrepostas as informações de hidrografia e linhas de transmissão para o estado de Minas Gerais. Uma nova análise espacial foi executada tendo como parâmetros todas as células de DNI (10 km x10 km) que interceptam cursos de água e, deste resultado, todas as células que interceptam linhas de transmissão. Esse passo proporcionou filtrar os locais com DNI igual ou maior que 5,48 que estão próximos a cursos d'água e linhas de transmissão. O Mapa 03 (Map 03 - Map of selected cities prone to system instalation) apresenta o resultado desta análise espacial.

O mapa com os limites de municípios de Minas Gerais foi obtido junto ao Instituto Brasileiro de Estatística e Geografia (IBGE). Este, sobreposto ao resultado do passo anterior, identificou 26 municípios que contêm células com $\mathrm{DNI} \geq 5,48$ próximas à cursos d'água e linhas de transmissão, e, portanto, candidatos à instalação de uma usina heliotérmica. $O$ resultado desta análise pode ser visto no Mapa 03 abaixo.

\section{MAPA 03 - MAPA DE CIDADES SELECIONADAS PROPENSAS A INSTALAÇÃO DO SISTEMA}

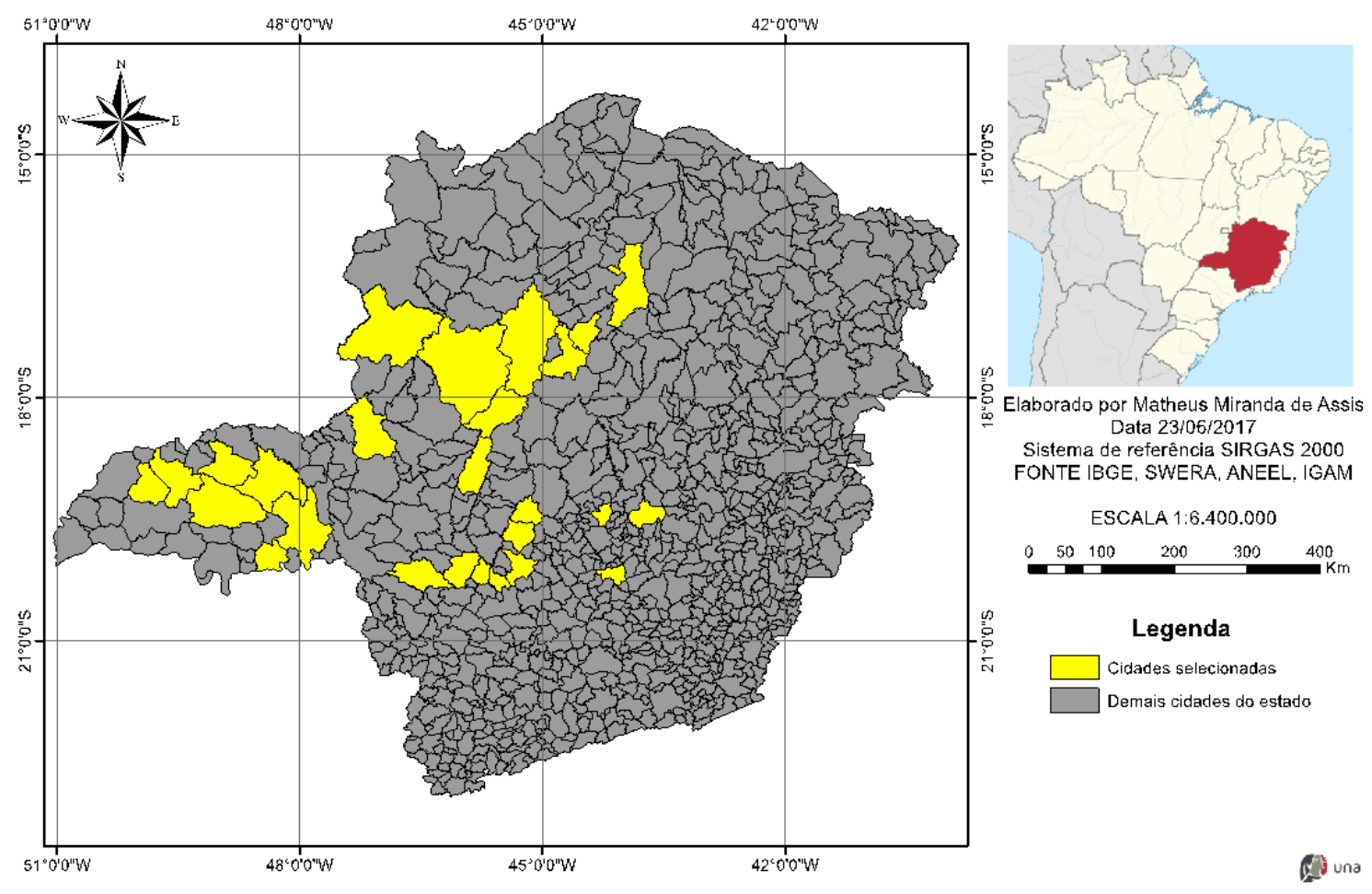

Disponível em: https://www.nucleodoconhecimento.com.br/engenharia-ambiental/potencial-degeracao 
Com um número elevado de locais propensos à instalação, aplicou-se um novo filtro para que fosse possível a escolha de um único município. O parâmetro escolhido para essa etapa foi o município que apresentasse a maior concentração de indústrias. Infere-se aqui que este parâmetro é um indicativo de município próspero, com economia em ascensão e que comportaria o financiamento de um projeto desta natureza. Além do que, o próprio complexo industrial poderia se envolver no projeto, arcando com os custos da instalação e beneficiando-se da energia produzida.

Como fonte de consulta para identificação, localização e quantificação de indústrias em Minas Gerais foram utilizados os dados disponibilizados pelo Cadastro Industrial MG, administrado pelo Sistema da Federação das Indústrias do Estado de Minas Gerais (FIEMG). A Tabela 1, a seguir, apresenta um resumo do resultado desta consulta.

Tabela 1 - Número de indústrias nos municípios de interesse do projeto no estado de Minas Gerais

\begin{tabular}{|l|l|l|l|l|l|}
\hline Cidades & Micro & Pequena & Média & Grande & Total \\
\hline Uberlândia & 137 & 384 & 87 & 22 & 630 \\
\hline Uberaba & 72 & 186 & 53 & 7 & 318 \\
\hline Sete Lagoas & 34 & 128 & 45 & 13 & 220 \\
\hline Montes Claros & 36 & 103 & 44 & 7 & 190 \\
\hline Ituiutaba & 12 & 42 & 8 & 3 & 65 \\
\hline Bom Despacho & 11 & 34 & 12 & 1 & 58 \\
\hline Paracatu & 14 & 32 & 5 & 1 & 52 \\
\hline João Pinheiro & 5 & 17 & 4 & 1 & 27 \\
\hline Brumadinho & 3 & 12 & 9 & 1 & 25 \\
\hline Várzea da Palma & 2 & 10 & 1 & 3 & 16 \\
\hline Bambuí & 2 & 6 & 0 & 1 & 9 \\
\hline Prata & 2 & 3 & 3 & 1 & 9 \\
\hline Martinho Campos & 1 & 6 & 2 & 0 & 9 \\
\hline
\end{tabular}




\begin{tabular}{|c|c|c|c|c|c|}
\hline Buritizeiro & 2 & 2 & 1 & 0 & 5 \\
\hline Iguatama & 0 & 3 & 1 & 0 & 4 \\
\hline $\begin{array}{l}\text { Conceição das } \\
\text { Alagoas }\end{array}$ & 0 & 2 & 1 & 0 & 3 \\
\hline $\begin{array}{l}\text { Monte Alegre de } \\
\text { Minas }\end{array}$ & 0 & 3 & 0 & 0 & 3 \\
\hline $\begin{array}{l}\text { São Gonçalo do } \\
\text { Abaeté }\end{array}$ & 0 & 1 & 1 & 0 & 2 \\
\hline $\begin{array}{l}\text { São Roque de } \\
\text { Minas }\end{array}$ & 0 & 1 & 0 & 0 & 1 \\
\hline Tiros & 0 & 0 & 1 & 0 & 1 \\
\hline
\end{tabular}

Fonte: CADASTRO INDUSTRIAL MG, 2017

De acordo com o observado na Tabela 1, Uberlândia/MG é o que apresenta o maior número de indústrias, principalmente de médio e grande porte. O Mapa 04 (Map 04 Map of médium and and large industries of Uberlândia city) ilustra a localização destes empreendimentos no referido município. 
MAPA 04 - MAPA DE INDÚSTRIAS DE MÉDIO E GRANDE PORTE DE UBERLÂNDIA
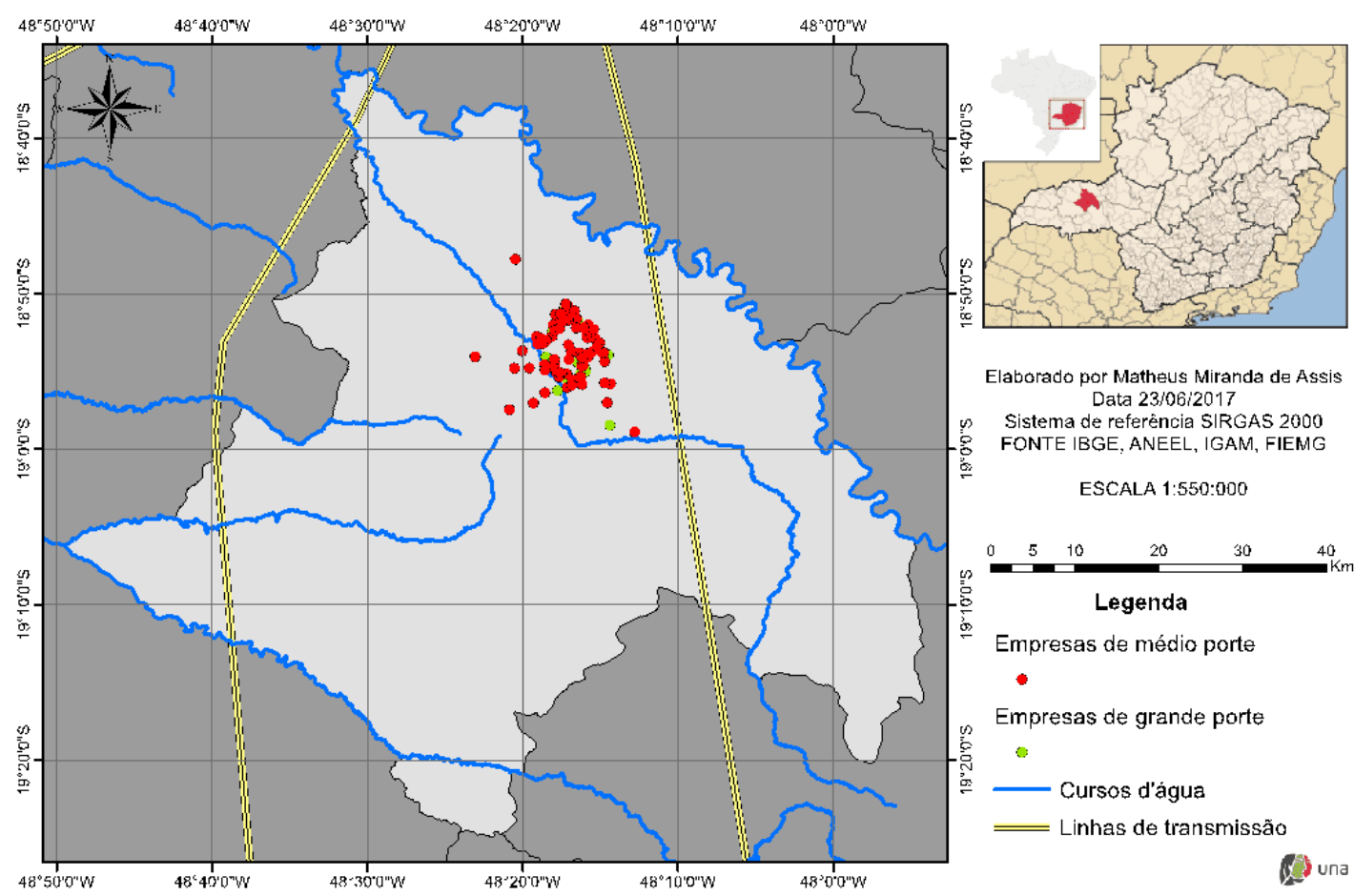

Para confecção do mapa hipsométrico, Mapa 05 (Map 05 - Hypsometric map of Uberlândia city), e do mapa de declividade Mapa 07 (Map 07 - Declivity map of Uberlândia city) do município de Uberlândia, Mapa 06, foram utilizadas imagens de radar Shuttle Radar Topograph Mission (SRTM) disponibilizadas pelo United States Geological Survey (USGS) com resolução espacial de 30 metros. Esta análise se fez necessária para se avaliar as regiões do município que apresentam menores índices de declividade. 


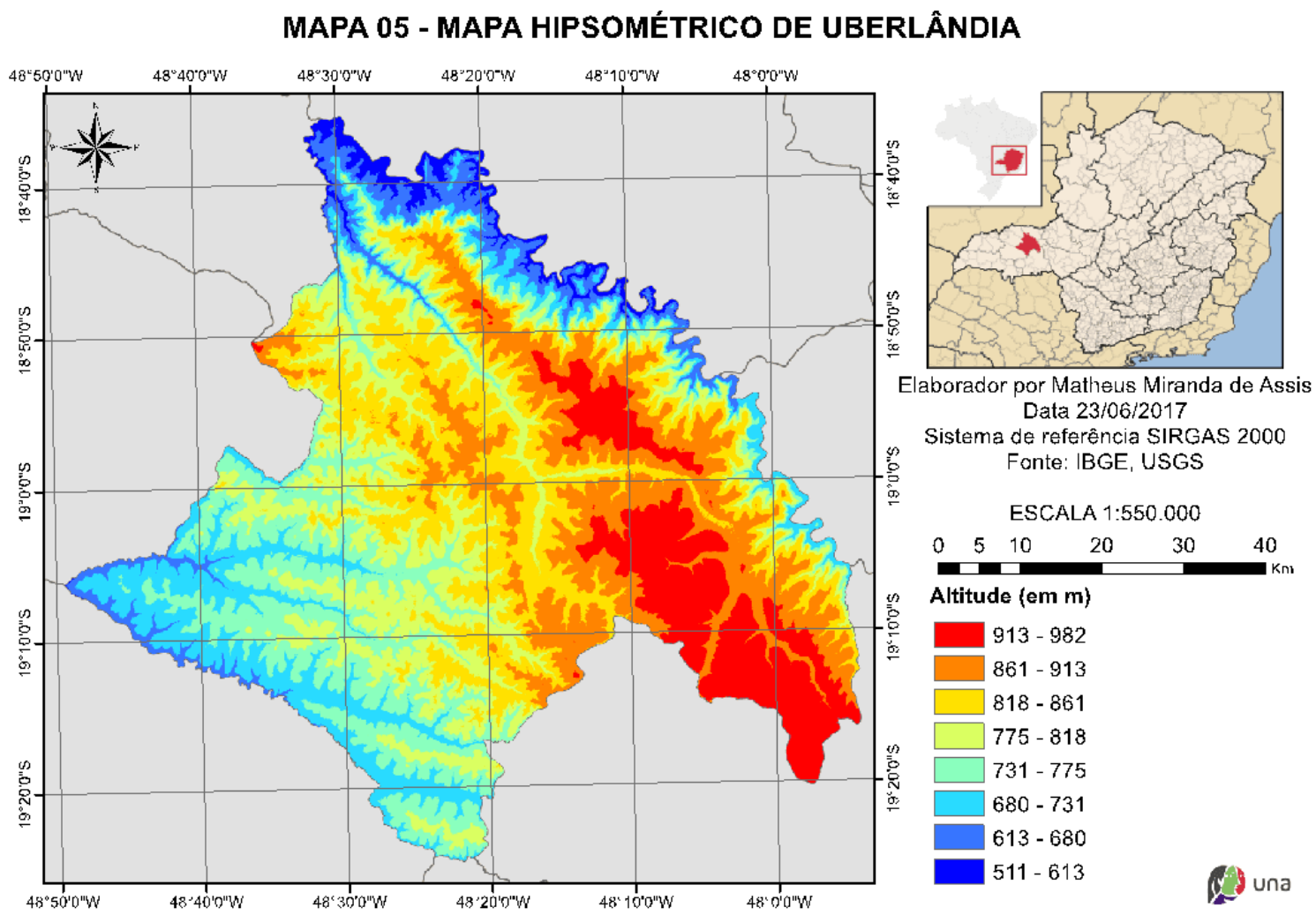

Disponível em: https://www.nucleodoconhecimento.com.br/engenharia-ambiental/potencial-degeracao 


\section{MAPA 06 - MAPA DE DECLIVIDADE DE UBERLÂNDIA}

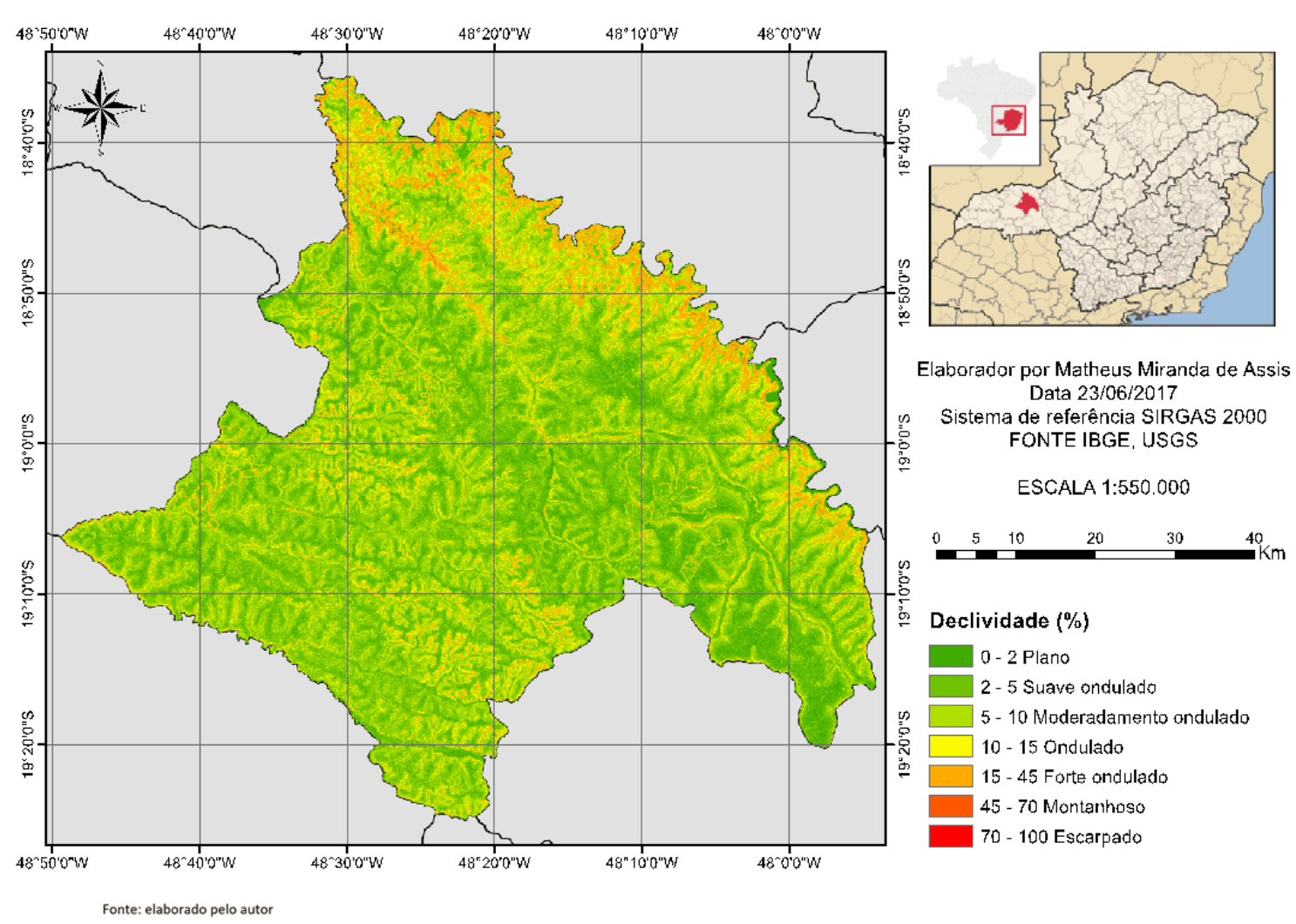

\section{RESULTADOS E DISCUSSÃO}

Através da metodologia explicitada no item anterior, identificou-se quatro áreas propícias à instalação do sistema heliotérmico no município de Uberlândia/MG, conforme mostrado no Mapa 08 (Map 8-Declivity map of selected areas in Uberlândia city).

Disponível em: https://www.nucleodoconhecimento.com.br/engenharia-ambiental/potencial-de- 
MAPA 07 - MAPA DE DECLIVIDADE DE ÁREAS SELECIONADAS DE UBERLÂNDIA

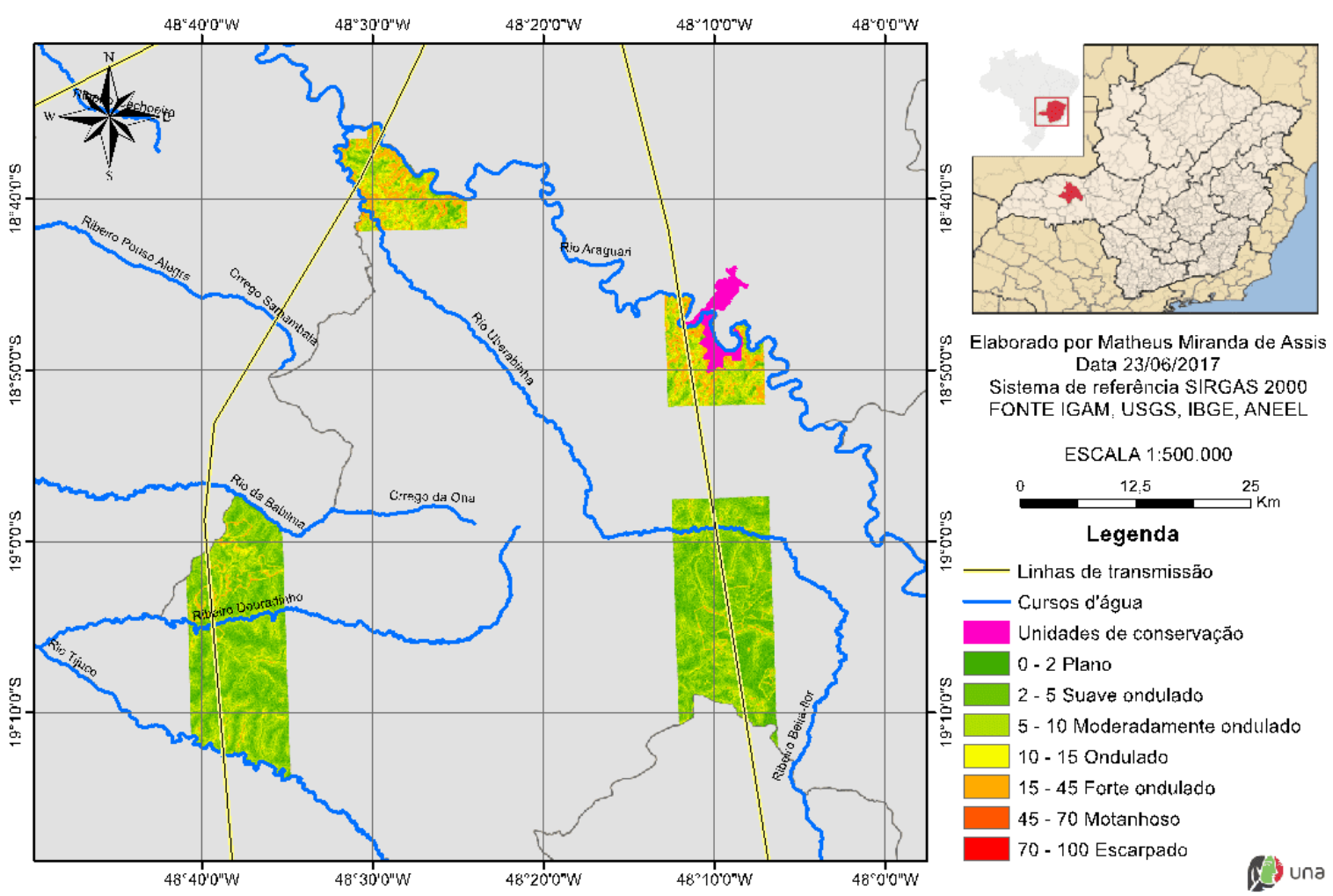

É possível notar, no mapa supramencionado, que as duas áreas mais ao norte apresentam relevo mais ondulado; fator que poderia encarecer à instalação de usinas heliotérmicas. Além disso, a região mais a nordeste possui uma área de conservação ambiental denominada Parque Estadual de Pau Furado; área que será descarta devido à necessidade de supressão vegetal para instalação de uma usina no local. Neste caso, sugere-se a implantação de usinas heliotérmicas em uma das áreas ao sul do município, que apresentam um relevo mais plano e proximidade a cursos d'água e linhas de transmissão.

Para melhor compreensão do processo sucessivo e encadeado de análise espacial realizadas neste trabalho, um roteiro e as funções executadas, encontra-se representado em um fluxograma na Figura 01.

Disponível em: https://www.nucleodoconhecimento.com.br/engenharia-ambiental/potencial-de- 
FIGURA 1 - FLUXOGRAMA DE ETAPAS EXECUTADAS NO ESTUDO

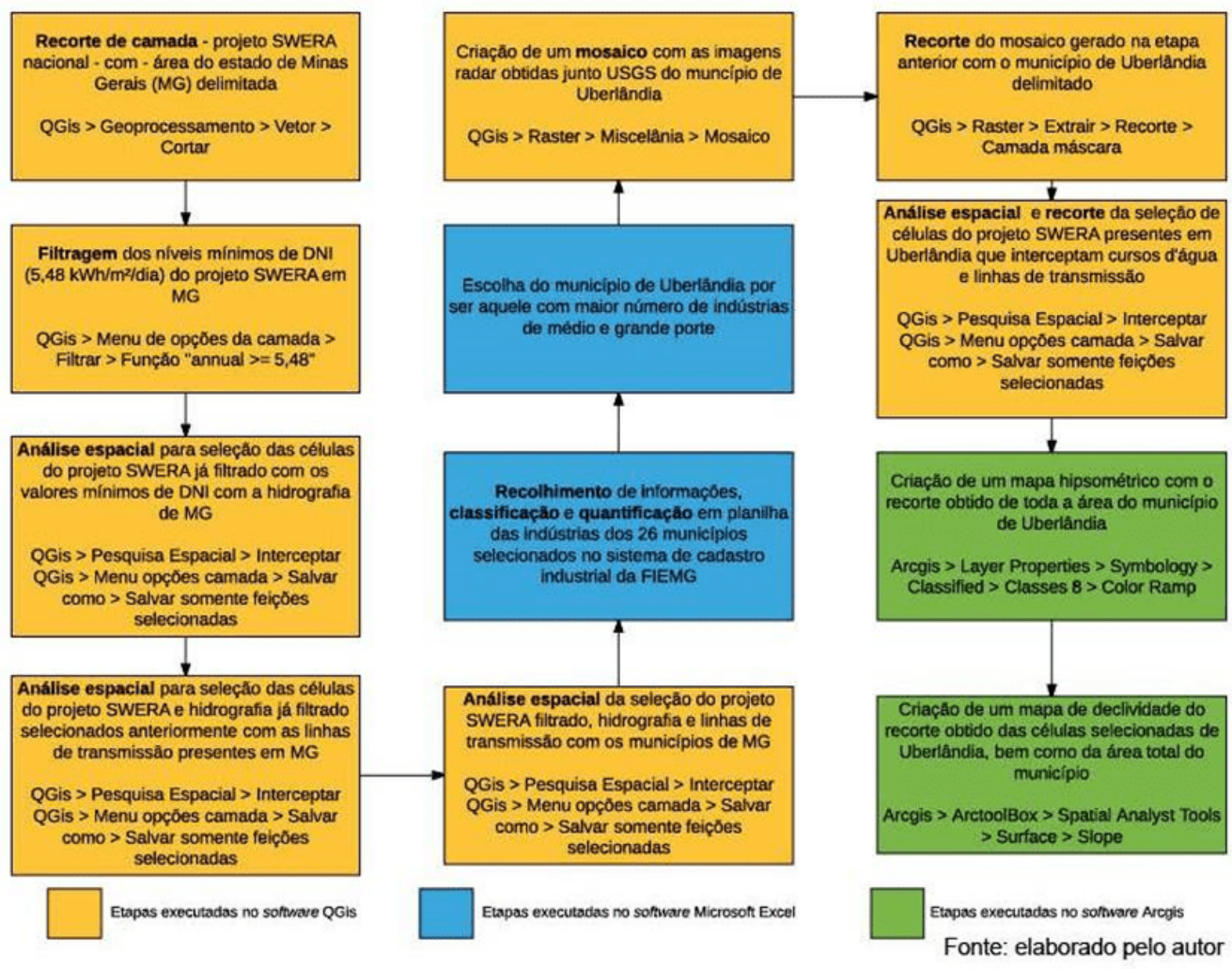

\section{CONCLUSÕES}

Diante das características locais das áreas definidas e das tecnologias de usinas heliotérmicas mencionadas no item 2 , sugere-se a instalação de usinas no modelo de torre central.

Conforme descrito no item 2.4, o modelo de torre central pode atingir temperaturas de até $1.000^{\circ} \mathrm{C}$. Isso torna possível utilizar turbinas de alta potência, possibilitando um elevado aumento de eficiência na geração de energia elétrica. Outra vantagem deste modelo encontra-se na localização de seu receptor de calor, que por ser instalado em uma área central da usina, permite uma maior eficiência no armazenamento térmico, o que garante maior tempo de operação nos períodos noturnos. Por último, ressaltase o baixo consumo de água no processo de refrigeração deste modelo, o que

Disponível em: https://www.nucleodoconhecimento.com.br/engenharia-ambiental/potencial-de- 
contribuiria para uma menor taxa de captação de água nas imediações das regiões propostas neste estudo.

O cruzamento de todas as informações relativas aos dados de radiação e fatores ambientais realizados nas análises espaciais nos aplicativos Quantum Gis e ArcGis, permitiram reduzir o universo do espaço geográfico do estado de Minas Gerais a duas pequenas áreas localizadas no município de Uberlândia/MG, as quais apresentam as características mais favoráveis à implantação de um empreendimento de produção de energia renovável com a instalação de uma usina heliotérmica no modelo de torre central.

As áreas selecionadas estão próximas a cursos de água e linhas de transmissão, o que permite o aporte de água ao sistema e a fácil interligação ao sistema elétrico nacional.

Ambas as áreas não são confrontantes de Unidades de Conservação, o que garante o respeito ao meio ambiente e, por fim, estão distantes do perímetro urbano, o que garante segurança á população.

\section{REFERÊNCIAS}

AGÊNCIA NACIONAL DE ENERGIA ELÉTRICA - ANEEL. Informações gerenciais $\begin{array}{llll}\text { setembro } & 2016 . & \text { Disponível em }\end{array}$ <http://www.aneel.gov.br/documents/656877/14854008/Boletim+de+Informações+G erenciais+-+3º +trimestre+de+2016/a4192798-adf3-4902-b2ae-098033e69f5c>. Acessado em 14 de jun. de 2017.

ALVES, Mariana Castro. Sol, primeira fonte de luz e energia. Gênero. № 59 . Revista Pré-univesp. Julho, 2016. Disponível em: <http://pre.univesp.br/sol-primeira-fonte-deluz-e-energia\#.V-FD6GVS37M> Acesso em: 20. Set. 2016. 
AZEVEDO, Verônica Wilma Bezerra. Estudo de localização de centrais termoelétricas solares de grande porte na região do semi-árido nordestino. Recife, PB. 2010.

BIANCHINI, Henrique Magalhães. Avaliação comparativa de sistemas de energia solar térmica. Rio de Janeiro, RJ. 2013.

BRASIL. Lei oㅜ 9.985, de 18 de julho de 2000. Regulamenta o art. 225, § 10, incisos I, II, III e VII da Constituição Federal, institui o Sistema Nacional de Unidades de Conservação da Natureza e dá outras providências. Brasília, 18 de julho de 2000.

CABRAL, Isabelle de Souza. SENNA, Pedro Rocha. TORRES, Adriana Cazelgrandi. Energia solar - Análise comparativa entre Brasil e Alemanha. Ln: IV CONGRESSO BRASILEIRO DE GESTÃO AMBIENTAL. Salvador, 2013.

CADASTRO INDUSTRIAL MG. Informação comercial atualizada e gratuita das indústrias mineiras. Disponível em <http://www.cadastroindustrialmg.com.br>. Acesso em: 16. Jun. 2017.

CAMARGOS, Ronaldo Sérgio Chacon; OLIVEIRA, Rafael Amaral de; SHAYANI, Rafael Amaral. Método para análise comparativa dos impactos técnicos da geração distribuída fotovoltaica concentrada e pulverizada. Revista Brasileira de Energia Solar, v. 7, n. 2, p. 115-122, 2017.

CEPEL, Centro de Pesquisas de Energia Elétrica. Energia Solar. [entre 2013 e 2016]. Disponível em: <http://www.cepel.br/linhas-de-pesquisa/menu/energia-solar.htm> Acesso em: 20. Set. 2016.

ENERGIA HELIOTÉRMICA. Radiação direta. 2015. Disponível em: < http://energiaheliotermica.gov.br/pt-br/glossario/radiacao-direta> Acesso em: 15 abr. 2017. 
IRENA, International Renewable Energy Agency. Statistics Time Series. Disponível em: <http://resourceirena.irena.org/gateway/dashboard/?topic=4\&subTopic=16> Acesso em: 15 abr. 2017.

KEMERICH, Pedro Daniel da Cunha. FLORES, Carlos Eduardo Balestrin. BORBA, Willian Fernando de. SILVEIRA, Rafael Borth da. FRANÇA, Jacson Rorigues.

KALOGIROU, S. Solar energy engineering: processes and systems. USA: Elsevier, 2009.

LODI, Cristiane. Perspectivas para a geração de energia elétrica no Brasil utilizando a tecnologia solar térmica concentrada. Rio de Janeiro, RJ. 2011.

PENAFIEL, Rafael Andrés Soria. Cenários de geração de eletricidade a partir de geradores heliotérmicos no Brasil: a influência do armazenamento de calor e da hibridização. Rio de Janeiro, RJ. 2011.

PEREIRA, Enio Bueno et al. Mapas de irradiação solar para o Brasil - Resultados do Projeto SWERA. São José dos Campos, SP. 2005.

PHILIBERT, C., FRANKL, P., DOBROTKOVA, Z.. Technology roadmap: Concentrating Solar Power. Internacional Energy Agency (IEA), 2010. Disponível em:

https://www.iea.org/publications/freepublications/publication/csp_roadmap.pdf>. Acesso em: 26. Mar. 2017.

PORTAL BRASIL. Capacidade elétrica atinge 149 mil Megawatts em novembro. Publicado: 02/01/2017. Disponível em: <http://www.brasil.gov.br/infraestrutura/2017/01/capacidade-eletrica-atinge-149-milmegawatts-em-novembro>. Acesso em: 26. Mar. 2017.

SILVA, Manuel António Pimenta da. Central de produção de energia eléctrica a partir de energia solar térmica. Lisboa, Portugal. 2013. 
SILVA, Gardenio Diogo Pimentel da. SOUZA, Marcelo José Raiol de. Análise de variáveis de projeto de sistema solar fotovoltaico utilizando o modelo SAM: uma comparação entre Belém, Fortaleza e Brasília. Belém, PA. 2013.

\section{APÊNDICE - REFERÊNCIA DE NOTA DE RODAPÉ}

3. Segundo Bianchini (2013), atualmente é o sistema mais empregado por apresentar menores perdas térmicas e ser mais econômico. O motor Stirling usa o calor para variar a pressão no interior de uma câmara de hidrogênio selado, fazendo os pistões produzirem energia mecânica.

Enviado: Março, 2020.

Aprovado: Junho, 2020. 